SHS Web of Conferences 12, 01090 (2014)

DOI: $10.1051 /$ shsconf/ 20141201090

(C) Owned by the authors, published by EDP Sciences, 2014

\title{
Comparing the Awareness of a New Donation System and Willingness to Pay of Japanese and International Climbers at Mount Fuji
}

\author{
Thomas Jones $^{1}$, Kiyotatsu Yamamoto ${ }^{2}$ \\ ${ }^{1}$ Graduate School of Governance Studies, Meiji University, TA Jimbocho Building, Research \\ Laboratory 501, 1-1 Kanda-Surugadai, Chiyoda-ku, Tokyo, Japan \\ ${ }^{2}$ Faculty of Agriculture Environmental Sciences for Sustainability, Iwate University 020-8550 Ueda 3- \\ 18-8, Morioka-City, Iwate, Japan
}

\begin{abstract}
In June 2013, Mount Fuji was nominated as a UNESCO World Heritage site. Subsequently, a new system was piloted encouraging climbers to make a donation of 1000 JPY to help improve environmental conservation. This research is part of a larger study from 2008 to 2014 monitoring the characteristics and behaviour of Fuji climbers. Specifically, this paper investigates Japanese and international climbers to compare their level of awareness and willingness to pay the new donation. Results revealed broad differences between Japanese and international climbers, with $71 \%$ of the latter unaware about the new fee prior to climbing, compared to only $16 \%$ of Japanese. $77 \%$ of Japanese supported the new fee compared to only $50 \%$ of international climbers. These findings seem to suggest that prior awareness is vital for compliance, as cross-analysis showed that among international climbers, $72 \%$ of those who knew in advance were willing to pay, compared to $43 \%$ of those without prior awareness. The new trial climbing fee will be extended for the entire 2014 season on a 24 hour basis, so these findings have implications for improved management based on a better understanding of market segments and more effective messaging to raise awareness, particularly among foreign climbers.
\end{abstract}

\section{Introduction}

In June 2013, Mount Fuji was listed as a United Nations Educational, Scientific and Cultural Organization (UNESCO) World Heritage Site (WHS), ending several years of speculation and intense debate. Fuji is the centrepiece of the Fuji-Hakone-Izu National Park, among the busiest in the world with over 110 million estimated annual visits. Visitation trends have shown positive growth in recent years, perhaps partly due to the impending WH designation. For example, the number of climbers increased 31\% from 231,542 in 2007 to 305,350 in 2008, the year when Fuji was first named on the tentative UNESCO list [1]. This was consistent with a longer-term increase - for example the number of climbers on the Yoshida route doubled from 110,400 in 1981 to 232,682 in 2013 [2].

Fuji's intense popularity results in spatial and temporal congestion that drew criticism from an ICOMOS report, galvanizing the bordering prefectures of Yamanashi and Shizuoka into action. Shortly after the official announcement of UNESCO listing, the prefectural governments announced 
the co-creation of a new trial system encouraging each climber to make a donation of 1000 JPY to support a range of environmental and cultural conservation initiatives. A 10 day trial for the new conservation donation system was successfully piloted from 25 July to 3 August 2013.

\section{Background and Research Aim}

Mount Fuji, Japan's tallest peak at $3776 \mathrm{~m}$, is located some 60 miles southwest of Tokyo on the border of Yamanashi and Shizuoka Prefectures. In pre-modern Japan it became the goal for guided groups of pilgrims known as the Fuji $k \bar{o}$, whose numbers are estimated to have topped ten thousand in 1877 [3]. This religious legacy, combined with Fuji's artistic heritage, formed the core components of Fuji's successful nomination as a UNESCO World Cultural Heritage site in 2013.

To cater for the pilgrims, all the Fuji trailhead towns had oshi houses which formed networks of religious functionaries attached to shrines and temples around the foot of the volcano. As well as disseminating the Fuji shinkō style of worship, they also provided accommodation for the pilgrims in their homes. With the help of subordinate sendatsu, the oshi organized logisitics such as porters and provided spiritual services including blessings, rites and ablutions. Pilgrims paid a package fee which included the devotional diet, purification and banners, as well as interpretation of local customs, thus ensuring a cost recovery mechanism for local communities. Their role as cultural mediators, combined with the substantial input for regional economies, have drawn parallels with current ecotourism practice [4].

However, in the pre and immediate postwar periods, a series of access infrastructure projects drastically altered Fuji's socio-economic circumstances, culminating in the construction of large scale approach roads. One example is the Subaru line, a toll road on Fuji's north face which was completed in time for the Tokyo Olympics in 1964 . This $30 \mathrm{~km}$ paved road transports cars, buses and bikes up to the $5^{\text {th }}$ station, located halfway up the mountain at an altitude of 2,300 meters above sea level. In doing so, it facilitates access to an estimated 3 million annual visitors of whom some $10 \%$ attempt to summit Japan's highest peak during the summer season of July and August. The impact of over 300,000 climbers results in economic inputs to the regional economy on the one hand, and strain on the environment, including visitor facilities such as toilets and trails, on the other.

The recent increase in climber numbers and WH accreditation process has prompted renewed debate on the issue of cost recovery mechanisms by management to mitigate such negative impacts. The toll roads such as the Subaru line do already represent an income stream with which to provide certain visitor services. They are supplemented by separate user fees for rest and shelter at the mountain huts and the introduction in 1999 of a voluntary tipping system for visitors using the public toilets [5]. As decision-making arrangements at Fuji are dominated by prefectural government, and Japan's national parks anyway have no specific entrance fee system, Shizuoka and Yamanashi launched a joint resolution to implement the new conservation donation system in 2013.

Although declared to be a kind of 'social experiment,' the pilot scheme was initially introduced without much preamble, with few opportunities for a range of stakeholders to voice their opinions about the new system and the multiple issues associated with paying for outdoor recreation. These range from issues such as 'double-taxation' to difficulties setting an equitable fee for different user segments, without driving some visitors away [6]. This research aims to fill that gap by comparing the attitudes of Japanese and international climbers to investigate their socio-economic profile, level of prior awareness of the new climbing fee and their willingness to pay the suggested donation.

\section{Method}

Fuji's four main trails all have trailheads at the 5th step that range in altitude from approximately 1400 meters at Gotemba to 2400 meters at Fujinomiya. The Yoshida route on the north face of the mountain has the highest volume of users due to its convenient access from the Kanto area. It was therefore selected as the target for this project because it has the largest market share, accounting for 
$58 \%$ of all climbers in 2013 . It was also reported to have large numbers of foreign climbers, although no official data exists to verify this.

These results are part of a larger survey which was conducted at Izumigataki Junction on the Yoshida route every summer (July-August) from 2008-2014, but only 2013 results are discussed here. Questionnaires were distributed in English and Japanese to climbers descending the Fuji-Yoshida trail the morning after having attempted to summit. After a pilot test, the main survey was conducted over four days in the peak month of August 2013, including weekdays and weekends. 420 usable Japanese and 232 English questionnaires were collected, making a total of 652. The self-administered questionnaires used open and closed questions to monitor socio-economic characteristics before investigating levels of awareness and willingness to pay the new fee.

Table 1. Overview of Questionnaire Sample

\begin{tabular}{llcc}
\hline Date & Day & ENG & JPN \\
\hline 6-Aug & TUES & 50 & 89 \\
7-Aug & WEDS & 32 & 104 \\
10-Aug & SAT & 89 & 122 \\
11-Aug & SUN & 61 & 114 \\
\hline
\end{tabular}

\section{Findings}

\subsection{Socio-economic Profile}

Among the English language sample, a total of 232 sheets were collected from respondents from 35 different countries. By continent, Asian climbers were most prolific $(n=93)$, followed by those from Europe $(n=58)$ and North America $(n=54)$. However, by country climbers from the U.S.A. $(n=46)$ were easily the most common. Two-thirds of foreign climbers were male, and 51\% were aged 20-29. $52 \%$ were currently living in Japan, with $48 \%$ living overseas. Most of the former category (60\%) had been living in the country for $1-3$ years, while the majority of the latter ( $72 \%)$ had come to Japan on holiday, with $55 \%$ staying for up to 2 weeks.

Table 2. Overview of Respondents' Socio-economic Profile.

\begin{tabular}{lrrrr}
\hline $\begin{array}{l}\text { Socio-economic } \\
\text { variable }\end{array}$ & $\begin{array}{c}\text { ENG } \\
(\mathbf{n}=\mathbf{2 3 2})\end{array}$ & \multicolumn{2}{c}{$\begin{array}{c}\text { JPN } \\
(\mathbf{n}=\mathbf{4 3 5})\end{array}$} \\
\hline & & & & \\
\hline Male & 154 & $66.7 \%$ & 215 & $51.1 \%$ \\
Female & 77 & $33.3 \%$ & 206 & $48.9 \%$ \\
\hline & & & & \\
\hline $10 \mathrm{~s}$ & 12 & $5.2 \%$ & 6 & $1.4 \%$ \\
$20 \mathrm{~s}$ & 117 & $50.6 \%$ & 171 & $40.2 \%$ \\
$30 \mathrm{~s}$ & 62 & $26.8 \%$ & 111 & $26.1 \%$ \\
$40 \mathrm{~s}$ & 20 & $8.7 \%$ & 65 & $15.3 \%$ \\
$>50$ & 20 & $8.7 \%$ & 72 & $16.9 \%$ \\
\hline & & & & \\
\hline$<\$ 20,000$ & 67 & $31.6 \%$ & 90 & $23.6 \%$ \\
$\$ 20,000-\$ 39,999$ & 56 & $26.4 \%$ & 129 & $33.8 \%$ \\
$\$ 40,000-\$ 59,999$ & 39 & $18.4 \%$ & 106 & $27.7 \%$ \\
$\$ 60,000-\$ 79,999$ & 10 & $4.7 \%$ & 27 & $7.1 \%$ \\
$>\$ 80,000$ & 40 & $18.9 \%$ & 30 & $7.9 \%$ \\
\hline & & & &
\end{tabular}


Among the Japanese language sample, a total of 420 sheets were collected from respondents from 35 of the total 46 different prefectures. The majority of Japanese climbers came from Kanto, better known as the Greater Tokyo Metropolitan area, especially Tokyo $(n=128)$ and Kanagawa $(n=64)$. The Japanese profile displayed a more even gender balance, with $49 \%$ females. Although the median age was young, $17 \%$ were aged 50 or over. A higher proportion of foreign climbers claimed to be in a low income bracket $(<\$ 20,000-32 \%)$, although the percentile of $<\$ 40,000$ was similar among both groups. More Japanese climbers checked the mid-income bracket $(\$ 40,000-\$ 59,999-28 \%)$, while more foreigners checked the upper-income bracket $(>\$ 80,000-19 \%)$.

\subsection{Awareness and Willingness to Pay}

Results revealed broadly different preferences, with Japanese more willing to pay than international climbers at all three suggested rates (Fig. 1). Crucially, $87 \%$ of Japanese supported the new donation at its officially suggested rate of $1000 \mathrm{JPY}$, compared to only $50 \%$ of international climbers. If the donation shrinks to 500JPY, the support rate increases to $95 \%$ and $72 \%$ respectively. Conversely if the donation rises to $3000 \mathrm{JPY}$, the support rate decreases to $37 \%$ and $22 \%$ respectively. Moreover, the median for the stated maximum amount that Japanese climbers were willing to pay was 2374JPY compared to $1850 \mathrm{JPY}$ for foreigners.

One explanatory factor seems to be the greater importance attached to the UNESCO label by Japanese climbers. $20 \%$ of Japanese respondents claimed the WH factor was the main reason they had decided to climb Fuji, and a further $29 \%$ acknowledging it was a contributory reason although they had already decided to climb anyway. This compared with $78 \%$ of international climbers for whom the UNESCO listing was not a reason, whereas only $9 \%$ stated it as the main reason for climbing. From a logistical perspective, the findings also suggest that prior awareness is vital for compliance, since $91 \%$ of Japanese climbers had been aware of the new system prior to their arrival on the mountain, compared to just $30 \%$ of foreigners. A further cross-analysis revealed that among international climbers, $72 \%$ of those who knew in advance were willing to pay, compared to $43 \%$ of those without prior awareness.

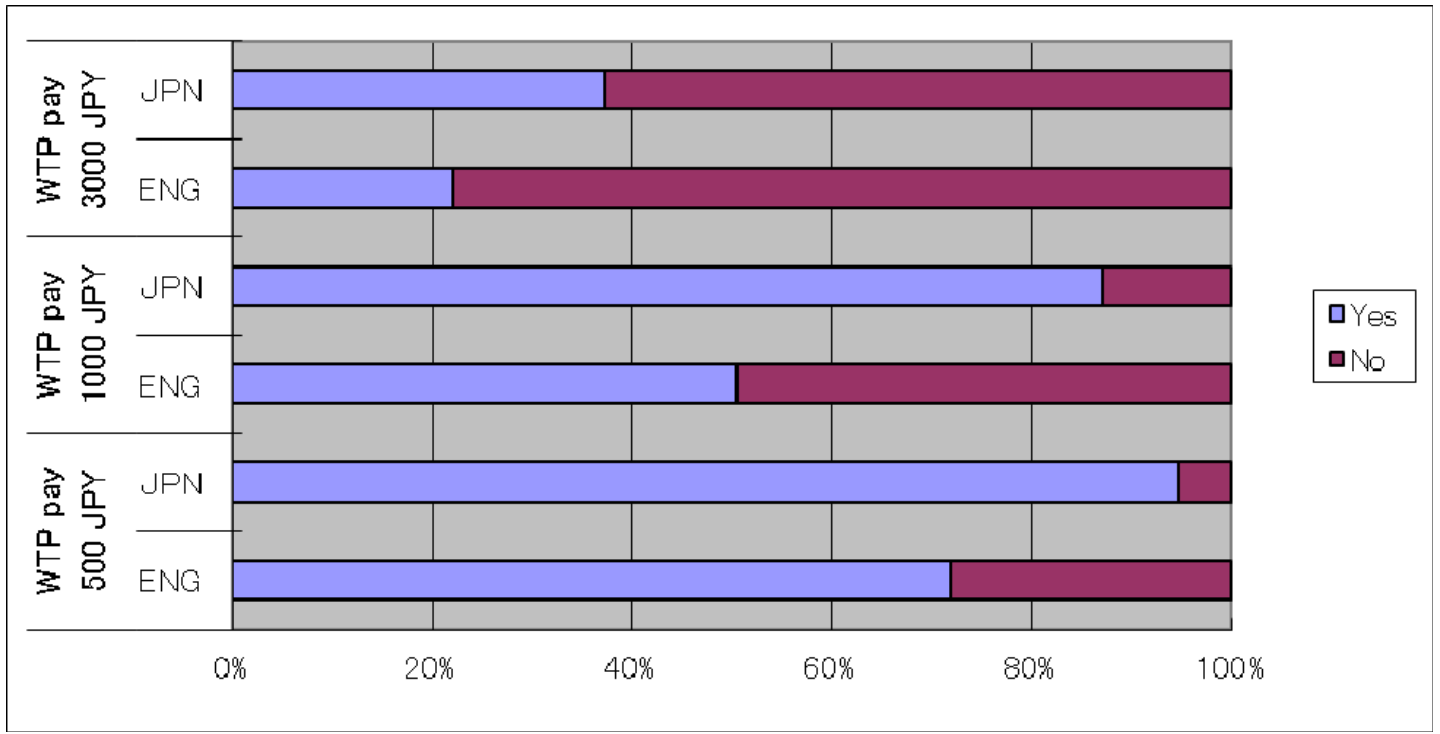

Figure 1. Cross Analysis of Willingness to Pay (WTP) Amongst Japanese and International Climbers 


\section{Discussion}

Although the new donation was in theory collected on a volunteer basis, the set-up of official checkpoints on all four trails prompted a high collection rate and there are now plans to extend the scheme throughout the 2014 season prior to the creation of a full management plan by 2015 as advised by ICOMOS. Collection of the donations thus represents a renewed determination on the part of management to mitigate the cluster of existing visitor impacts such as congestion of trail and toilets that have not been resolved - and may even have been exacerbated - by Mount Fuji's 2013 UNESCO listing. Yet the new policy risks being misinterpreted as knee-jerk reactionism given the lack of prior investigation into visitor attitudes. Moreover, from a theoretical standpoint, it raises some thorny issues related to charging for access to amenities such as national parks, protected for the benefits of tax-paying domestic audiences, and WH destinations that are of 'outstanding universal value.' For notwithstanding the elusive goal of a single intrinsic value that people of all cultures agree on, the reality of UNESCO sites is a complex mesh of contested use and non-use values [7].

In short, this paper identified four main findings from a questionnaire surveying the climbers' attitudes to the 2013 pilot test. The primary finding of a greater willingness to pay amongst Japanese climbers can be explained in terms of three interlinked explanatory factors that will now be discussed. Firstly, there is a lack of prior awareness on the part of international climbers that is most likely to be linked to the lack of English language information about the new policy and the minor press exposure which it has received compared to the coverage by domestic media channels. Next, a larger proportion of the English-speaking respondents were found to be from the lowest-income bracket. This corroborates findings from previous studies which identified a large proportion of students among the international climbers [8]. Lastly, 48\% of foreign climbers were in Japan on holiday with 55\% staying for up to 2 weeks, during which time they travel around the country making multiple stops at different destinations, thereby reducing their propensity to pay at Fuji.

Nonetheless these findings must be treated as preliminary and non-exhaustive. For example it is quite plausible that other factors such as patriotism could have affected the results by inspiring greater willingness to pay among Japanese climbers. Moreover, as 2013 was the first year of implementation more research is surely needed to monitor attitudes to the new conservation donation system now that the implementation period has been extended to incorporate the entire 2014 season. The research also had certain limitations, namely that the survey period did not coincide with the donation period. Moreover, the availability of only two languages - English and Japanese - may have added an unintended bias. In short, more ongoing monitoring is needed as a vital step toward seeking to understand climber behaviour with a view to improving rates of awareness and willingness to pay.

\section{Conclusion}

This paper investigated different attitudes among Japanese and international climbers to compare their level of awareness and willingness to pay the new 1000 JPY donation implemented after Fuji was listed as a UNESCO World Heritage site in 2013. Results from the questionnaire survey have four main implications for policy-makers. Crucially, Japanese climbers showed a greater willingness to pay the donation than their international counterparts. Based on these results, three interlinked factors were discussed as possible explanations. Firstly, $71 \%$ of international climbers were unaware of the system prior to climbing, possibly due to the lack of English language information promoting the new policy. Next, a larger proportion of the English-speaking respondents (32\%) were found to be from the lowest-income bracket which could also affect their willingness to pay. Lastly, $48 \%$ of foreign climbers were holiday-makers in Japan suggesting that Fuji may be just one stop on a multi-stop tour.

The principal implication for policy-makers is that prior awareness is vital for compliance, as cross-analysis revealed that $72 \%$ of international climbers who had prior knowledge of the donation were willing to pay, compared to $43 \%$ of those without prior awareness. As the new system has already been extended for the entire 2014 season on a 24 hour basis, these findings have implications 
for improved management based on a better understanding of market segments and more effective multi-lingual messaging to raise awareness, particularly among foreign climbers.

\section{References}

1. $\mathrm{MOE}$

2. Fuji Yoshida Safety Centre $6^{\text {th }}$ station

3. N. Murakushi, Kokuritsu kōen seiritsushi no kenkyū: Kaihatsu to shizen hogo no kakushitsu o chüshin $n i$ [The history of the establishment of the national parks: The feud between development and nature conservation]. Tokyo: Hōsei University (2005)

4. T. Itō, Trail and climber management and its cost recovery from the climbers at Mt. Fuji in Edo Period. J. of the Japanese Forest Soc 91 (2009)

5. H. Sayama and M. Nishida "Transition of the Beautification and Cleaning Activities in Mt. Fuji Area after World War II. ” Journal of the Japanese Institute of Landscape Architecture, 64, 5, 485488 (2001).

6. S.R. Martin, A policy implementation analysis of the recreation fee demonstration program: convergence of public sentiment, agency programs and policy principles. Journal of Park and Recreation Administration, 17, 3, 15-34 (1999)

7. B.S. Frey, "The evaluation of cultural heritage: Some critical issues." In Economic Perspectives on Cultural Heritage, edited by Michael Hutter and Ilde Rizzo, London: Macmillan. 31-49 (1997)

8. T. Jones, Y. Kato, K. Yamamoto and S. Aramaki, "The Current State of International Climbers at Mount Fuji: Evidence from 2008-2012 Monitoring Surveys.” Journal of Fujiology, 10, 2, 33-38 (2013) 